Document downloaded from:

http://hdl.handle.net/10251/176314

This paper must be cited as:

Marco-Jiménez, F.; Borrás-Pérez, S.; Garcia-Dominguez, X.; D Auria, G.; Vicente Antón, JS.; Marin, C. (2020). Roles of host genetics and sperm microbiota in reproductive success in healthy rabbit. Theriogenology. 158:416-423.

https://doi.org/10.1016/j.theriogenology.2020.09.028

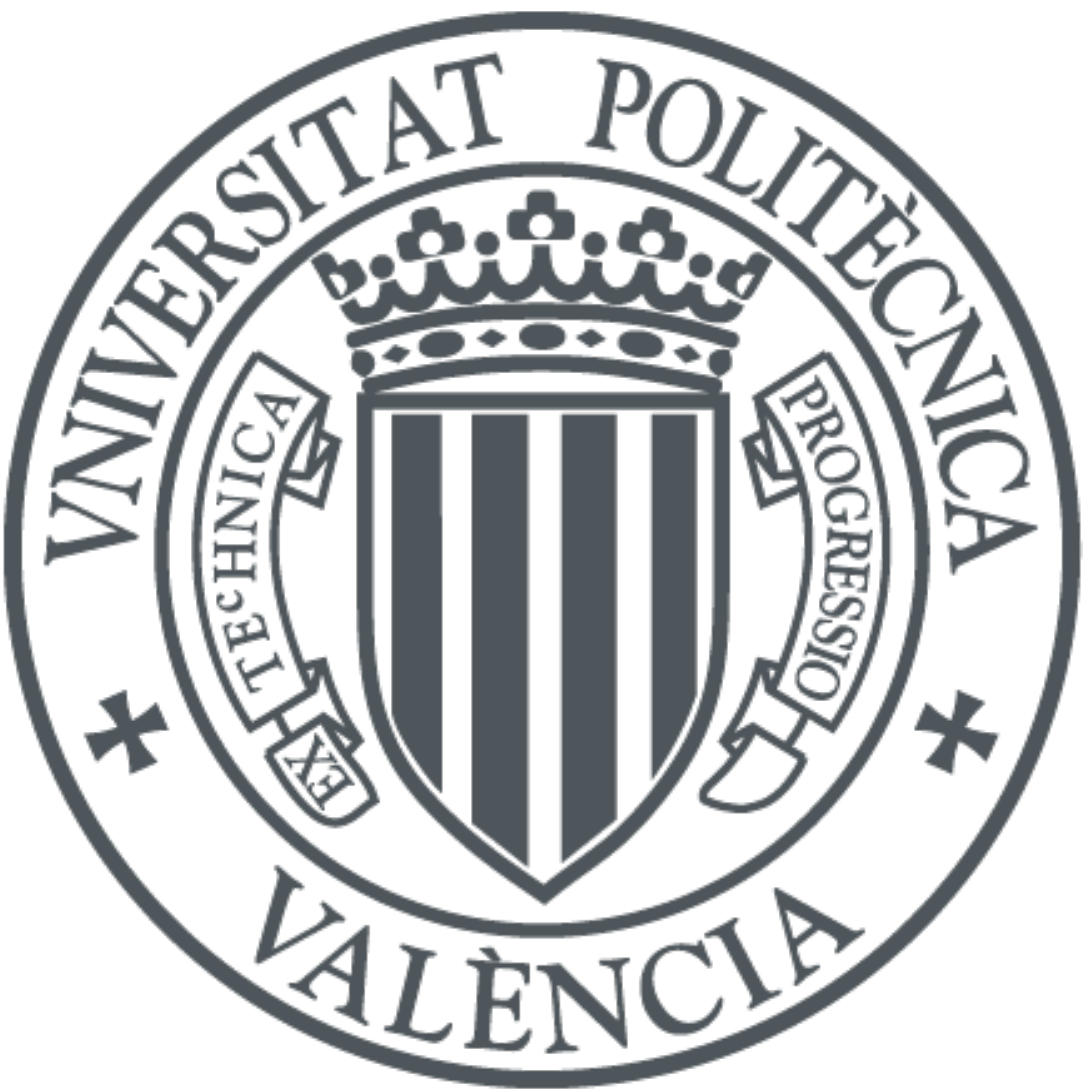

The final publication is available at

https://doi.org/10.1016/j.theriogenology.2020.09.028

Copyright Elsevier

Additional Information 


\section{Roles of host genetics and sperm microbiota in reproductive success in healthy}

rabbit

Francisco Marco-Jiménez ${ }^{1 *}$, Sara Borrás ${ }^{1}$, Ximo Garcia-Dominguez ${ }^{1}$, Giuseppe D'Auria $^{2}$, Jose Salvador Vicente ${ }^{1}$, Clara Marin ${ }^{3}$

${ }^{1}$ Institute of Science and Animal Technology, Laboratorio de Biotecnología de la Reproducción, Universitat Politècnica de València, Valencia, 46022.

${ }^{2}$ Servicio de Secuenciación y Bioinformática, Fundación para el Fomento de la Investigación Sanitaria y Biomédica de la Comunidad Valenciana (FISABIO-Salud Pública), Valencia, Spain.

${ }^{3}$ Instituto de Ciencias Biomédicas, Facultad de Veterinaria, Universidad Cardenal Herrera-CEU, CEU Universities, Avenida Seminario s/n, 46113 Moncada, España.

Corresponding author:

*Prof. PhD Francisco Marco-Jiménez, Laboratory of biotechnology of reproduction. Institute of Science and Animal Technology (ICTA) at the Universitat Politècnica de València, C/Camino de Vera s/n, 46022 Valencia, Spain.

Email address: fmarco@dca.upv.es.

Tel.: +3496 38794335; fax: +34963877439

\section{Highlights}

- Fertility differentials among inbred lines are not predicted by routine semen analysis

- Host genetic diversity affects the fertility rate

- Host genetic diversity affects the bounty of bacteria in sperm microbiota

- Sperm microbiota exhibit an inbred line-specific variation in bacterial occurrence

- Symbiotic sperm microbiota could be potentially correlated with reproductive disorders 


\section{Abstract}

Although the effects of sperm microbiota and sperm quality have been described previously, recent studies provide evidence that female genital modifications triggered by seminal components could be of significant importance to identify some disturbances associated with fertility. So, sperm microbiota could play a key role in sperm quality, contributing to fertilisation. To understand how sperm microbiota diversity is influenced by the host genetics, the symbiotic bacteria in four inbred lines raised in the same animal facility and their effects on sperm quality and fertility were analysed. Forty healthy rabbits from four selected Spanish commercial lines were used in this research (three based on litter performance, designated A, V and LP, and one selected for daily body weight gain, called R). Significant variations in the seminal concentration, morphology and some motion parameters were found among inbred lines, but sperm motility and viability were similar among inbred lines. After mating, inbred lines selected for litter size had the same fertility rate, significantly higher than inbred line selected for body weight $(82 \pm 3.3 \%$, $79 \pm 3.5 \%$ and $89 \pm 4.5 \%$ versus $61 \pm 3.7 \%$, for the A, V and LP vs R lines, respectively, $\mathrm{p}<0.05)$. Bacteria belonging to Proteobacteria, Firmicutes, Fusobacteria and Bacteroidetes were identified in sperm microbiota. At genus level, the bacterial community composition in the sperm microbiota was influenced by host genetics. A total of $35,16,34$, and 51 genera were accurately detected in the A, V, LP, and R lines, respectively. Moreover, Enhydrobacter, Ferruginibacter, Myroides Paracoccus, Rheinheimera, Tepidiphilus, Tetradesmus obliquus and Thauera genera were present only in the inbred lines selected for litter size. Moreover, the discriminant analysis revealed Lysinibacillus and Flavobacterium genera as potential biomarkers for fertility. Thus, these two genera may play a key role in fertility. Our results demonstrated the 
existence of a rabbit inbred line-specific variation in bacterial occurrence in sperm microbiota. Moreover, fertility differentials among inbred lines that were not predicted by routine semen analysis could be partly explained by the symbiotic state of the semen microbiota.

Keywords: Microbiota; 16S rRNA; semen; fertility; inbred line

\section{INTRODUCTION}

Several studies have described that microbiota, the microorganisms present in any tissue in an animal organism, are involved in homeostasis and health [1-3], including those of the male and female genital tracts [4]. The negative effect of bacteria on spermatozoa physiology, viability, motility and fertility are thus well known [5-7]. Nevertheless, the presence of bacteria in semen is also found in fertile individuals with normal sperm parameters $[8,9]$. Based on these findings, recent research has postulated that the presence of a specific bacterial milieu might be necessary for normal sperm function $[4,10,11]$. In this sense, several authors hypothesised that a symbiotic and dysbiotic state of the sperm microbiota could be related to sperm quality [7,12]. Besides, changes in female genital molecular profiles triggered by seminal elements is an emerging field in the advancement of fertility science $[13,14]$.

Even though hosts co-evolved with the microbiota, current knowledge on microbiota and their interactions with the host is still in its infancy [15]. However, in several animal species the role of host genetics in the gut microbiota composition has been demonstrated [16-20], but the effects of host genetics remain unclear [21]. Nevertheless, it is well known that host genetics influence sperm quality, fertility and prolificacy [22-24]. 
Similarly, studies based on seminal plasma proteins have described host genetic effects on compositions [25-27]. The importance of the microbiome in host status has prompted the development of new methodologies focused on control of the host microbiome, either by decreased the number of harmful taxa or reinstating beneficial taxa and their functions [28]. The extent to which host genetics can modulate the sperm microbial composition remains unknown. Therefore, we hypothesised that host genetics could affect the symbiotic sperm microbiota of different rabbit inbred lines selected for different traits. A large cohort including four lines within the same animal facility was formed with the aim of detecting significant associations between genetics and sperm microbiota composition and its effects on sperm quality.

\section{MATERIALS AND METHODS}

\subsection{Ethics}

All experiments involving animals complied with Directive 2010/63/EU EEC and institutional guidelines of the Universitat Politècnica de València Ethical Committee. All animals were bred and euthanised in an approved animal facility (approval number ES462500001091). Experimental protocols were conducted under the supervision of the animal welfare committee in charge of this animal facility (research code: 2018/VSC/PEA/0116).

\subsection{Animals}

The experiment was conducted from October 2018 to February 2019, with animals from four selected Spanish commercial lines (three based on litter performance, designated A, V and LP, and one selected on daily body weight gain, called R) reared at the Universitat 
Politècnica de València. The foundation process of line A began in 1976 by sampling New Zealand White rabbits, reared by farmers near Valencia (Eastern Spain). After three generations without selection, the synthetic breed has since 1980 been selected using a family index based on litter size at weaning [29]. Line V was founded in 1980, by mating crossbred animals that were the progeny of four specialised breeds based on litter performance. Since then, this line has been selected to increase litter size at weaning [29]. Foundation of the LP line was started in 2003 by selecting females from commercial farms that showed extremely long productive lives and prolificacy near or above the average of the Spanish commercial rabbit population. This line has been selected since its foundation to increase litter size at weaning [30]. In V and LP, animals are selected based on the best linear unbiased predictions (BLUP) obtained with a repeatability animal model. Line R comes from the fusion of two inbred lines selected on daily body weight gain, one founded in 1976 with Californian rabbits reared by Valencian farmers and another founded in 1981 with rabbits belonging to specialised lines selected on daily body weight gain [31]. The method of selection has always been by individual selection on post-weaning daily gain. The last generations of selection considered in the present study were $50^{\text {th }}, 44^{\text {th }}$ and $11^{\text {th }}$ and $36^{\text {th }}$ generations for lines A, V, LP and R, respectively [3234]. All inbred lines had been kept closed since their foundation. Maternal lines (A, V, LP) are medium-sized animals, while paternal line (R) are large-sized animals. The average body weight for males used in our study was $3916 \pm 405 \mathrm{~g}$ and $5426 \pm 493 \mathrm{~g}$ for maternal lines and paternal line, respectively (data expressed as mean \pm standard deviation). 
All animals were housed at the Universitat Politécnica de Valencia animal facilities in flat deck indoor cages $(75 \times 50 \times 30 \mathrm{~cm})$, with free access to water and commercial pelleted diets (minimum of $15 \mathrm{~g}$ of crude protein per $\mathrm{kg}$ of dry matter (DM), $15 \mathrm{~g}$ of crude fibre per $\mathrm{kg}$ of DM, and 10.2 MJ of digestible energy (DE) per $\mathrm{kg}$ of DM). The photoperiod was set to provide $16 \mathrm{~h}$ of light and $8 \mathrm{~h}$ of dark, and the room temperature was regulated to keep temperatures between $14^{\circ} \mathrm{C}$ and $28^{\circ} \mathrm{C}$. The hygiene and sanitary measures used correspond to those usual in a commercial rabbit farm, the cages were previously disinfected with pressurized steam and once the males were housed, flame torch to burn of the hair was used weekly and feed and water equipment were cleaned and disinfected monthly. All animals are periodically checked by the vet.

\subsection{Male reproductive performance: sperm traits and fertility rate}

Forty healthy rabbit bucks (10 by genetic group) were used for semen collection. Semen samples were collected weekly for 10 weeks, and pooled by group. Collections were performed on the same day of the weeks. A total of 40 pools (10 for each host genetic group) were analysed. Quality sperm parameters (concentration, sperm abnormality, acrosome integrity and sperm motility) were performed using the methodology described by Viudes-De-Castro et al. [35] to assess the sperm quality. Briefly, three $20 \mu \mathrm{L}$ aliquots of each pool were taken. The first sample was evaluated for individual sperm motility and motion parameters using the Integrated Semen Analysis System version 1.0.17 (ISAS; Projectes i Serveis R+D). For each sample, four microscopic fields were analysed, and a minimum of 200 sperm evaluated. The following sperm activity variables were assessed: sperm motility (\%), progressive motility (\%), curvilinear velocity (VCL, $\mu \mathrm{m} / \mathrm{s})$, straightline velocity (VSL, $\mu \mathrm{m} / \mathrm{s}$ ), average path velocity (VAP, $\mu \mathrm{m} / \mathrm{s}$ ), linearity coefficient (LIN;

calculated as $(\mathrm{VSL} / \mathrm{VCL}) \times 100)$, straightness coefficient $(\mathrm{STR})$, wobble coefficient 
(WOB; VSL/VAP $\times 100)$, the amplitude of lateral head displacement $(\mathrm{ALH}, \mu \mathrm{m})$ and beat cross frequency $(\mathrm{BCF}, \mathrm{Hz})$. The second sample was assessed for the percentage of live spermatozoa (viability, VIA) using the LIVE/DEAD sperm viability kit (Molecular ProbesTM), which basically consists of two DNA-binding fluorescent dye: a membranepermeant dye, SYBR-14, and a conventional dead-cell dye, propidium iodide. The third sample was fixed with glutaraldehyde solution and observed by phase-contrast at $\times 400$ magnification to calculate the concentration, in a Thoma-Zeiss counting cell chamber, and evaluate both the percentages of intact apical ridge and abnormal sperm (based on morphological abnormalities of head, neck, mid-piece and tail) [36].

Management of animals in the different genotypes was the same, using natural mating; bucks and does began reproduction from 17 to 18 weeks of age [37]. The experiments were performed following the second delivery to ensure sexual maturity in all animals (all animals aged between 8 and 15 months old). One ejaculate by the male was collected (on Monday) three days before mating two times to assig female the same day (Friday). Only lactating and not lactating multiparous females were considered ( 3 to 6 deliveries). Females were mated 11 days after kindling. On day 12 post-mating, each doe was tested for pregnancy by abdominal palpation, and non-pregnant does were mated back. The same female was mating twice as a maximum along this study. In order to minimise the increase of inbreeding, mating between close relatives was avoided, so that mates could not have common grandparents. In addition, the contribution of bucks to the next generation was equalised; thus, as previously stated, males were selected within sire families [32]. To avoided the individual variations between males, all males contributed with a minimum of 10 matings. The number of does that gave birth by the number of mating was recorded (fertility rate). 


\subsection{RNA extraction, qPCR validation, library prep, sequencing}

An aliquot of the two first pooled samples for each host genetic group was centrifuged at $7400 \mathrm{~g}$ for $10 \mathrm{~min}$ at $4^{\circ} \mathrm{C}$, and the supernatant was obtained and stored at $-80^{\circ} \mathrm{C}$ until analysis. A total of 8 pools (2 for each host genetic group) were analysed. Total DNA was extracted using the NucliSens easyMag automated system (bioMérieux, Marcy l'Etoile, France) according to the manufacturer's instructions. We used microbial genomic DNA (5 $\mathrm{ng} / \mu \mathrm{l}$ in $10 \mathrm{mM}$ Tris $\mathrm{pH} 8.5$ ) to initiate the protocol. The V3-V4 region of the bacterial 16S rRNA gene sequences was amplified using the primer pair 341F-805R [38], containing the gene-specific sequences and Illumina adapter overhang nucleotide sequences. Primer sequences were forward primer: (5’TCGTCGGCAGCGTCAGATGTGTATAAGAGACAGCCTACGGGNGGCWGCA G3’; reverse primer: 5'GTCTCGTGGGCTCGGAGATGTGTATAAGAGACAGGACTACHVGGGTATCT AATCC3'). After 16 S rDNA gene amplification, the multiplexing step was performed using the Nextera XT Index Kit (FC-131-1096). We ran $1 \mu \mathrm{l}$ of the PCR product on a Bioanalyzer DNA 1000 chip to verify the size; the expected size on a Bioanalyzer trace is $\sim 550 \mathrm{bp}$. After size verification, the libraries were sequenced using a $2 \times 300$ pb pairedend run (MiSeq Reagent kit v3 (MS-102-3001)) on a MiSeq Sequencer, following the manufacturer's instructions (Illumina, Inc., San Diego, CA, USA).

\subsection{Sequence analyses}

Demultiplexed paired FASTQ sequence were imported into the QIIME2 v2018.11 for analysis. Quality control was carried out using the DADA2 pipeline incorporated into QIIME2 [39]. The DADA2 program filtered out phiX reads removed chimeric sequences 
and assigned reads into Amplicon Sequence Variants (ASVs). Taxonomic annotation was obtained using the SILVA v132 database [40]

\subsection{Statistical analyses}

Sperm traits data were analysed with a repeated-measures general linear model with both host genetic group and week as repeated measures for each replicate. Data were expressed in the least-square means \pm standard error of means. A chi-square test was used to test differences in fertility rate at birth between groups and female reproductive status (nonlactating and lactating). The level of significance was set at $p<0.05$. Statistical analyses were performed using the SPSS 21.0 software package (SPSS Inc., Chicago, Illinois, USA, 2002).

Sequencing statistical analyses were done using QIIME2 and R Statistical Software Version 1.1.383. To determine significance in alpha diversity, non-parametric KruskalWallis tests to complete pairwise comparisons between host genetics (A, V, R y LP) were performed. Non-parametric Kruskal-Wallis comparisons were performed using Faith's Phylogenetic Diversity to determine if there were statistical differences in species richness in the host genetic. Box-and-whisker plots for species richness and evenness were generated using QIIME2. A Venn diagram was drawn up to show the shared and unique OTUs among groups, based on the occurrence of OTUs in a sample group regardless of their relative abundance [41]. Shared taxa present in all four groups $(100 \%$ core threshold) were defined as the core microbiome. Analysis of the composition of microbiomes (ANCOM) test was run to determine if they change significantly between genetic traits (litter performance and daily body weight gain) [42]. Statistical analyses for beta diversity were completed by calculating Bray-Curtis distance using QIIME2. 
Principle Coordinate Analysis (PCoA) plots were generated for the inbreeding line sample from Bray-Curtis distances using QIIME2.

\section{RESULTS}

A cohort of 40 livestock rabbit males belonging to four different inbred lines (A, V, LP and R) was analysed. No health and reproductive problems were found in the females used in this study. In fact, the selection process was not altered during and after the sampling period in any inbred line.

\subsection{Sperm quality and fertility}

Semen characteristics are shown in Table 1. The host genetic group had no effect on the total motility and VCL, or on viability of the spermatozoa. However, males from V and LP lines showed a higher concentration and an abnormal sperm rate, while males from A line showed a lower intact apical ridge rate $(\mathrm{p}<0.05)$. Additionally, the host genetic group affected motion parameters (Table 1). Males from the LP line showed a higher VSL and WOB $(p<0.05)$, while males from the V and R lines showed a higher ALH $(p<0.05)$. Males from the R line showed a lower STR $(p<0.05)$.

We assessed male offspring fertility as the relation of pregnant does, and mating does by a male. A total of 494 matings were recorded (Table 2). The host genetic group from $\mathrm{R}$ line exhibit significantly impaired fertility (Table $2, \mathrm{p}<0.05$ ).

\subsection{S rRNA sequence output overview}


A total of 8 samples, 2 per host genetic group, were used for downstream bioinformatics analysis. The MiSeq sequencing yielded a total of 702,606 raw sequences with an average read length of $434.9 \pm 49.90 \mathrm{pb}$. The average number of reads per sample was 87,825 with the minimum number of reads per sample being 66,282 and the maximum number of reads per sample being 114,640. A total of 93,355 ASVs were generated. A total of 9,180 chimeric sequences were removed from the dataset with a total of 84,175 sequences left for ASVs table generation and database alignment. After filtering a total of 1,384 unique sequences were left for taxonomic assignment. The datasets generated and analysed are available at NCBI's BioProject PRJEB37988.

\subsection{Diversity}

Alpha diversity was assessed through species evenness and species richness measures. Rarefaction analysis indicated that the number of OTUs per sample reached a maximum, indicating that the sequencing effort captured the diversity of the majority of the samples

(Fig. 1). There were no significant differences in species evenness for host genetics (A, $\mathrm{V}, \mathrm{R}$ and LP, $\mathrm{p}=0.08$ ). However, statistically significant differences were seen in species richness in relation to genetic origin $(p=0.05$ and $p=0.04$ for Shannon index and observed OTUs, respectively. Fig. 2).

The results of the PERMANOVA test using Bray-Curtis dissimilarity showed no significant differences in beta diversity of sperm samples regarding hosting genetics $(\mathrm{p}=$ 0.016). Results of the PERMANOVA indicated that there were significant differences in the microbial community composition in relation to genetic origin $(p=0.044)$. There is a separation of points in the PCoA plot between the host genetics, displaying that there are differences in the microbial community composition (Fig. 3B), indicating that the 
dominant bacterial species in litter size selected lines were more similar in comparison with $\mathrm{R}$ line.

\subsection{Abundant genera}

To better understand how the microbial community composition changes between host genetics, we examined which organisms were present at different taxonomic levels and their relative abundance levels. For instance, we identified 25 phyla, with Proteobacteria (44.8\%), Firmicutes (37.3\%), Fusobacteria (22.1\%), Bacteroidetes (10.3\%) and Actinobacteria $(8.1 \%)$ being the most abundant across all samples (expressed as an average percentage overall bacterial reads). To examine the existence of an identifiable common core microbiome [43], we defined a core as the group of members shared among the microbial community and represented the core by overlapping areas in the circles in a Venn diagram, at $97 \%$ identity. A total of 242 genera of bacteria were detected in all groups. Among them, 122, 84, 109 and 128 genera were detected in the A, V, LP, and R lines, respectively (Fig. 3A). Thirty-three genera were shared by all inbred lines. Interestingly, several genera were specifically found in each line. A total of 35, 16, 34, and 51 genera were detected in the A, V, LP, and R lines, respectively (Fig. 3A). Moreover, 8 genera were specific bacteria in the lines selected by litter size. The Enhydrobacter, Ferruginibacter, Myroides Paracoccus, Rheinheimera, Tepidiphilus, Tetradesmus obliquus and Thauera genera were shared across A, V and LP lines, respectively. The relative abundances were $0.46,0.37,0.29,0.29,0.50,0.57,0.27$ and $0.47 \%$, respectively. An ANCOM analysis was performed to identify change between genetic traits. We identified 2 bacteria genera (Lysinibacillus and Flavobacterium) that were significantly abundant in daily body weight gain for the selected line (R line, Fig. $4)$. 


\section{DISCUSSION}

The aim of this study was to evaluate for the first time whether there were reproducible differences in the sperm microbiota across several inbred commercial rabbit lines population located at the same genetic nucleus and kept under similar conditions. Although the effects of sperm microbiota and sperm quality have been described previously [7,10-12], the present study provides the first description of the influence of host genetics on the composition and abundance of sperm microbiota. Despite the small sample size, we found a linkage between inbred line and sperm microbiota diversity, and we should not forget that all animals were bred within the same animal facility in a closed nucleus system which notably reduces the potential impacts of undetected bias among host genetics. Moreover, we explored the microbial content of the sperm using fertile bucks. Till now, and given the limited number of studies, it is still unclear whether the presence of specific bacterial communities has the potential to influence sperm function [7].

The sperm microbiomes of inbred rabbit lines evaluated here were dominated by sequences representative of the phyla Proteobacteria, Firmicutes and Fusobacteria. These phyla commonly accounted for more than $78 \%$ of the total microbial populations detected. These findings were similar to those reported in other studies [7,12]. The core sperm microbiome was represented by 242 genera, including Fusobacterium, Delftia and Parvimonas dominant genus [7]. The results at the genus level showed that the bacterial 
community composition in the sperm microbiota was influenced by the inbred line, owing to their different genetic origin. Thus, it was surprising that the relative abundances were $13.4 \%, 7.9 \%, 7.5 \%$ and $22.0 \%$ in the A, V, LP and R line, respectively. However, the criteria used to select the founder animals of the inbred lines and for the selection criteria applied afterwards throughout the generations of selection could be primarily responsible for abundance and specific bacteria in the sperm microbiota [32]. However, no corroborating reports on the effect of genetic origin in the sperm microbiota have been published to date.

The relevance of the genetic line to explain the variation in fertility is well documented [22-24]. In this regard, several studies described notable differences, including a decline in reproductive success [44,45] and a higher disease incidence [32] in $\mathrm{R}$ line in comparison with lines selected by litter size. In our study, significant variations in the seminal concentration, morphology and motion parameters were found among all host genetics. However, we also found that similar motility and viability rates were recorded, indicating that independently of their host genetics, males produced sufficient sperm of sufficient quality to maximise the probability of impregnating the female. Hence, similar fertility rates among the A, V and LP lines were observed. Therefore, the slight changes observed in the seminal traits could be considered biologically irrelevant. However, again the reproductive performance of the $\mathrm{R}$ line resulted in a noticeable decrease in fertility, consistent with previous results $[44,45]$. There is extensive evidence that the correlation between conventional semen parameters and fecundation is complicated [46,47]. In this context, we found that all host genetics possessed high-quality semen, based on practices commonly used in the insemination centre [36]. However, routine semen analysis does not measure the fertilising potential of spermatozoa and the complex changes that occur 
in the female reproductive tract before fertilisation [48]. Based on our findings, we hypothesise that female genital modifications triggered by seminal components could be of significant importance to identify some disturbances associated with fertility. How sperm microbiota might alter the maternal environment is now well documented [49]. Even though the current evidence is clear that sperm microbiota is not required to achieve pregnancy, several studies have demonstrated that the events induced by sperm microbiota at insemination may 'program' the maternal environment and/or immune system to accommodate the semi-allogeneic conceptus and optimise pregnancy outcomes $[14,49]$. Specifically, semen elicits an immediate inflammatory response in the female genitalia [14,49-51]. In fact, in mice it has been demonstrated that a lack of sperm microbiota exposure at conception alters the phenotype in subsequent offspring [52]. In this regard, our results provide insight into the nature of the sperm microbiota and suggest that surveying the symbiotic sperm microbiota might be useful for improving fertility management.

In this study, the PCoA results showed that sperm microbiota bacterial communities in A, V and LP were more similar, indicating that the dominant bacterial species in litter size selected lines were more similar in comparison with $\mathrm{R}$ line. The results at the genus level indicated that 8 genera including Enhydrobacter, Ferruginibacter, Myroides, Paracoccus, Rheinheimera, Tepidiphilus, Tetradesmus obliquus and Thauera were specific bacteria in the lines selected by litter size. Besides, several genera were explicitly found in each line. Specifically, a total of 48 genera were particular bacteria in the R line (supplementary material), demonstrating that specific accumulation of these genera would occur by genetic susceptibility. Note that all animals had been kept at the same closed genetic nucleus since its foundation and cared for under similar conditions, 
which minimised potential bias in the results. Taken together, our results demonstrate the existence of a host genetics-microbiome interaction in sperm microbiota. So, we propose that symbiotic sperm microbiota could be taken into consideration by the artificial insemination industry. For instance, in mice, it has been demonstrated that an increase in the colonisation of Bacteroides and Prevotella disrupted spermatogenesis and sperm motility [53]. In this study, the relative abundance of Bacteroides and Prevotella on $\mathrm{R}$ line was significantly higher than in litter size selected lines $(2.71 \%$ and $1.78 \%$ vs 1.68 and $0.31 \%$ in overall species for $\mathrm{R}$ vs litter size selected lines, respectively). Thus, these two genera may play a key role in fertility, or it could suggest that the differential phenotypic characteristics already described in this line, both for females and males at the endocrine level and for the proteome and enzymatic activity of the seminal plasma, have repercussion on the microbiota, making it a potential biomarker of reproductive disorders. In addition, the statistical analysis of sperm microbiota composition identified Lysinibacillus and Flavobacterium as predictive biomarkers. We found a positive correlation in the $\mathrm{R}$ line in comparison with litter size selected lines. Meanwhile, earlier studies have identified Flavobacterium in sperm microbiota in human [54,55], porcine [56] and bovine [57]. Lysinibacillus has not previously been identified in sperm microbiota, but this bacillus has been found in the female urogenital microbiota in several species [58-60]. This could be relevant in relation to the demonstrated associations between sperm microbiota and fertility.

\section{CONCLUSION}

As the first metagenomic survey of sperm microbiota using next-generation sequencing in rabbit, our results demonstrated the existence of a host genetics-microbiome interaction 
in sperm microbiota. In addition, fertility differentials among inbred lines that were not predicted by routine semen analysis could be explained in part by the symbiotic and dysbiotic state of the sperm microbiota. Our data provide an excellent starting point for further sperm microbiota research investigating changes associated with reduced fertility, conservation and the use of probiotics in order to develop new semen extenders.

\section{REFERENCES}

[1] Schroeder BO, Bäckhed F. Signals from the gut microbiota to distant organs in physiology and disease. Nat Med 2016;22:1079-89. doi:10.1038/nm.4185.

[2] Mahboubi MA, Carmody LA, Foster BK, Kalikin LM, VanDevanter DR, LiPuma JJ. Culture-Based and Culture-Independent Bacteriologic Analysis of Cystic Fibrosis Respiratory Specimens. J Clin Microbiol 2016;54:613-9. doi:10.1128/JCM.02299-15.

[3] Moreno I, Codoñer FM, Vilella F, Valbuena D, Martinez-Blanch JF, JimenezAlmazán $\mathrm{J}$, et al. Evidence that the endometrial microbiota has an effect on implantation success or failure. Am. J. Obstet. Gynecol., vol. 215, Mosby Inc.; 2016, p. 684-703. doi:10.1016/j.ajog.2016.09.075.

[4] Altmäe S, Franasiak JM, Mändar R. The seminal microbiome in health and disease. Nat Rev Urol 2019;16:703-21. doi:10.1038/s41585-019-0250-y.

[5] Reichart M, Kahane I, Bartoov B. In Vivo and In Vitro Impairment of Human and Ram Sperm Nuclear Chromatin Integrity by Sexually Transmitted Ureaplasma urealyticum Infection1. Biol Reprod 2000;63:1041-8. doi:10.1095/biolreprod63.4.1041.

[6] Hosseinzadeh S. Co-incubation of human spermatozoa with Chlamydia trachomatis serovar E causes premature sperm death. Hum Reprod 2001;16:2939. doi:10.1093/humrep/16.2.293.

[7] Baud D, Pattaroni C, Vulliemoz N, Castella V, Marsland BJ, Stojanov M. Sperm microbiota and its impact on semen parameters. Front Microbiol 2019;10:234. doi:10.3389/fmicb.2019.00234.

[8] Cottell E, Harrison RF, McCaffrey M, Walsh T, Mallon E, Barry-Kinsella C. Are seminal fluid microorganisms of significance or merely contaminants? Fertil Steril 2000;74:465-70. doi:10.1016/S0015-0282(00)00709-3.

[9] Rodin DM, Larone D, Goldstein M. Relationship between semen cultures, leukospermia, and semen analysis in men undergoing fertility evaluation. Fertil Steril 2003;79:1555-8. doi:10.1016/S0015-0282(03)00340-6.

[10] Hou D, Zhou X, Zhong X, Settles ML, Herring J, Wang L, et al. Microbiota of the seminal fluid from healthy and infertile men. Fertil Steril 2013;100. doi:10.1016/j.fertnstert.2013.07.1991.

[11] Weng S-L, Chiu C-M, Lin F-M, Huang W-C, Liang C, Yang T, et al. Bacterial communities in semen from men of infertile couples: metagenomic sequencing reveals relationships of seminal microbiota to semen quality. PLoS One 2014;9:e110152. doi:10.1371/journal.pone.0110152. 
[12] Godia M, Ramayo-Caldas Y, Zingaretti L, Lopez S, Rodriguez-Gil JE, Yeste M, et al. A RNA-seq characterization of the porcine sperm microbiome. BioRxiv Genomics 2020:2020.03.16.994244. doi:10.1101/2020.03.16.994244.

[13] Bromfield JJ, Schjenken JE, Chin PY, Care AS, Jasper MJ, Robertson SA. Maternal tract factors contribute to paternal seminal fluid impact on metabolic phenotype in offspring. Proc Natl Acad Sci U S A 2014;111:2200-5. doi:10.1073/pnas.1305609111.

[14] Álvarez-Rodríguez M, Martinez CA, Wright D, Rodríguez-Martinez H. The role of semen and seminal plasma in inducing large-scale genomic changes in the female porcine peri-ovulatory tract. Sci Rep 2020;10:5061. doi:10.1038/s41598020-60810-z.

[15] Guven-Maiorov E, Tsai CJ, Nussinov R. Structural host-microbiota interaction networks. PLoS Comput Biol 2017;13:e1005579. doi:10.1371/journal.pcbi.1005579.

[16] Zhang C, Zhang M, Wang S, Han R, Cao Y, Hua W, et al. Interactions between gut microbiota, host genetics and diet relevant to development of metabolic syndromes in mice. ISME J 2010;4:232-41. doi:10.1038/ismej.2009.112.

[17] Zhao L, Wang G, Siegel P, He C, Wang H, Zhao W, et al. Quantitative genetic background of the host influences gut microbiomes in chickens. Sci Rep 2013;3:1163. doi:10.1038/srep01163.

[18] Goodrich JK, Waters JL, Poole AC, Sutter JL, Koren O, Blekhman R, et al. Human genetics shape the gut microbiome. Cell 2014;159:789-99. doi:10.1016/j.cell.2014.09.053.

[19] Roehe R, Dewhurst RJ, Duthie C-A, Rooke JA, McKain N, Ross DW, et al. Bovine Host Genetic Variation Influences Rumen Microbial Methane Production with Best Selection Criterion for Low Methane Emitting and Efficiently Feed Converting Hosts Based on Metagenomic Gene Abundance. PLoS Genet 2016;12:e1005846. doi:10.1371/journal.pgen.1005846.

[20] Camarinha-Silva A, Maushammer M, Wellmann R, Vital M, Preuss S, Bennewitz $\mathrm{J}$. Host genome influence on gut microbial composition and microbial prediction of complex traits in pigs. Genetics 2017;206:1637-44. doi:10.1534/genetics.117.200782.

[21] Fan P, Bian B, Teng L, Nelson CD, Driver J, Elzo MA, et al. Host genetic effects upon the early gut microbiota in a bovine model with graduated spectrum of genetic variation. ISME J 2020;14:302-17. doi:10.1038/s41396-019-0529-2.

[22] Vicente JS, Viudes-de-Castro MP, Lavara R, Lavara F. Effect of male line on prolificacy from does inseminated with low sperm doses. In: Universitat Politècnica de València, editor. 7th World Rabbit Congr., Valencia: 2000, p. 2737.

[23] Safaa HM, Vicente JS, Lavara R, Viudes De Castro MP. Semen evaluation of two selected lines of rabbit bucks. World Rabbit Sci., vol. 16, 2008, p. 141-8.

[24] Broekhuijse MLWJ, Soštarić E, Feitsma H, Gadella BM. The value of microscopic semen motility assessment at collection for a commercial artificial insemination center, a retrospective study on factors explaining variation in pig fertility. Theriogenology 2012;77:1466-1479.e3. doi:10.1016/j.theriogenology.2011.11.016.

[25] Casares-Crespo L, Talaván AM, Viudes-de-Castro MP. Can the Genetic Origin Affect Rabbit Seminal Plasma Protein Profile along the Year? Reprod Domest Anim 2016;51:294-300. doi:10.1111/rda.12680.

[26] Casares-Crespo L, Fernández-Serrano P, Viudes-de-Castro MP. Proteomic 
characterization of rabbit (Oryctolagus cuniculus) sperm from two different genotypes. Theriogenology 2019;128:140-8. doi:10.1016/j.theriogenology.2019.01.026.

[27] Casares-Crespo L, Fernández-Serrano P, Vicente JS, Marco-Jiménez F, Viudesde-Castro MP. Rabbit seminal plasma proteome: The importance of the genetic origin. Anim Reprod Sci 2018;189:30-42. doi:10.1016/j.anireprosci.2017.12.004.

[28] Malla MA, Dubey A, Kumar A, Yadav S, Hashem A, Abd Allah EF. Exploring the Human Microbiome: The Potential Future Role of Next-Generation Sequencing in Disease Diagnosis and Treatment. Front Immunol 2018;9:2868. doi:10.3389/fimmu.2018.02868.

[29] Estany J, Baselga M, Blasco A, Camacho J. Mixed model methodology for the estimation of genetic response to selection in litter size of rabbits. Livest Prod Sci 1989;21:67-75. doi:10.1016/0301-6226(89)90021-3.

[30] Sánchez JP, Theilgaard P, Mínguez C, Baselga M. Constitution and evaluation of a long-lived productive rabbit line. J Anim Sci 2008;86:515-25. doi:10.2527/jas.2007-0217.

[31] Estany J, Camacho J, Baselga M, Blasco A. Selection response of growth rate in rabbits for meat production. Genet Sel Evol 1992;24:527. doi:10.1186/1297-968624-6-527.

[32] El Nagar AG, Sánchez JP, Ragab M, Mínguez C, Baselga M. Genetic variability of functional longevity in five rabbit lines. Animal 2020:1-9. doi:10.1017/S1751731119003434.

[33] Ragab M, Baselga M. A comparison of reproductive traits of four maternal lines of rabbits selected for litter size at weaning and founded on different criteria. Livest Sci 2011;136:201-6. doi:10.1016/J.LIVSCI.2010.09.009.

[34] Mínguez C, Sanchez JP, El Nagar AG, Ragab M, Baselga M. Growth traits of four maternal lines of rabbits founded on different criteria: comparisons at foundation and at last periods after selection. J Anim Breed Genet 2016;133:303-15. doi:10.1111/jbg.12197.

[35] Viudes-de-Castro MP, Mocé E, Lavara R, Marco-Jiménez F, Vicente JS. Aminopeptidase activity in seminal plasma and effect of dilution rate on rabbit reproductive performance after insemination with an extender supplemented with buserelin acetate. Theriogenology 2014;81:1223-8. doi:10.1016/j.theriogenology.2014.02.003.

[36] Lavara R, Mocé E, Lavara F, Viudes De Castro MP, Vicente JS. Do parameters of seminal quality correlate with the results of on-farm inseminations in rabbits? Theriogenology 2005;64:1130-41. doi:10.1016/j.theriogenology.2005.01.009.

[37] El Nagar AG, Sánchez JP, Ragab M, Mínguez C, Baselga M. Genetic variability of functional longevity in five rabbit lines. Animal 2020;14:1111-9. doi:10.1017/S1751731119003434.

[38] Klindworth A, Pruesse E, Schweer T, Peplies J, Quast C, Horn M, et al. Evaluation of general 16S ribosomal RNA gene PCR primers for classical and next-generation sequencing-based diversity studies. Nucleic Acids Res 2013;41. doi:10.1093/nar/gks808.

[39] Caporaso JG, Kuczynski J, Stombaugh J, Bittinger K, Bushman FD, Costello EK, et al. QIIME allows analysis of high-throughput community sequencing data. Nat Methods 2010;7:335-6. doi:10.1038/nmeth.f.303.

[40] Callahan BJ, McMurdie PJ, Rosen MJ, Han AW, Johnson AJA, Holmes SP. DADA2: High-resolution sample inference from Illumina amplicon data. Nat Methods 2016;13:581-3. doi:10.1038/nmeth.3869. 
[41] Zaura E, Keijser BJ, Huse SM, Crielaard W. Defining the healthy "core microbiome" of oral microbial communities. BMC Microbiol 2009;9:259. doi:10.1186/1471-2180-9-259.

[42] Mandal S, Van Treuren W, White RA, Eggesbø M, Knight R, Peddada SD. Analysis of composition of microbiomes: a novel method for studying microbial composition. Microb Ecol Heal Dis 2015;26. doi:10.3402/mehd.v26.27663.

[43] Lozupone CA, Hamady M, Kelley ST, Knight R. Quantitative and qualitative beta diversity measures lead to different insights into factors that structure microbial communities. Appl Environ Microbiol 2007;73:1576-85. doi:10.1128/AEM.01996-06.

[44] Vicente JS, Llobat L, Viudes-de-Castro MP, Lavara R, Baselga M, Marco-Jiménez F. Gestational losses in a rabbit line selected for growth rate. Theriogenology 2012;77:81-8. doi:10.1016/j.theriogenology.2011.07.019.

[45] Vicente J, Llobat M, Jiménez-Trigos E, Lavara R, Marco-Jiménez F. Effect of embryonic and maternal genotype on embryo and foetal survival in rabbit. Reprod Domest Anim 2013;48:402-6. doi:10.1111/rda.12087.

[46] Mocé E, Graham JK. In vitro evaluation of sperm quality. Anim Reprod Sci 2008;105:104-18. doi:10.1016/j.anireprosci.2007.11.016.

[47] Virtanen HE, Jørgensen N, Toppari J. Semen quality in the 21 st century. Nat Rev Urol 2017;14:120-30. doi:10.1038/nrurol.2016.261.

[48] Wang C, Swerdloff RS. Limitations of semen analysis as a test of male fertility and anticipated needs from newer tests. Fertil Steril 2014;102:1502-7. doi:10.1016/j.fertnstert.2014.10.021.

[49] Bromfeld JJ. A role for Seminal plasma in modulating pregnancy outcomes in domestic species. Reproduction 2016;152:R223-32. doi:10.1530/REP-16-0313.

[50] Rodríguez-Martínez H, Kvist U, Saravia F, Wallgren M, Johannisson A, Sanz L, et al. The physiological roles of the boar ejaculate. Soc Reprod Fertil Suppl 2009;66:1-21.

[51] Alvarez-Rodriguez M, Atikuzzaman M, Venhoranta H, Wright D, RodriguezMartinez H. Expression of Immune Regulatory Genes in the Porcine Internal Genital Tract Is Differentially Triggered by Spermatozoa and Seminal Plasma. Int J Mol Sci 2019;20. doi:10.3390/ijms20030513.

[52] Bromfield JJ, Schjenken JE, Chin PY, Care AS, Jasper MJ, Robertson SA. Maternal tract factors contribute to paternal seminal fluid impact on metabolic phenotype in offspring. Proc Natl Acad Sci U S A 2014;111:2200-5. doi:10.1073/pnas.1305609111.

[53] Ding N, Zhang X, Zhang X Di, Jing J, Liu SS, Mu YP, et al. Impairment of spermatogenesis and sperm motility by the high-fat diet-induced dysbiosis of gut microbes. Gut 2020. doi:10.1136/gutjnl-2019-319127.

[54] Mändar R, Punab M, Borovkova N, Lapp E, Kiiker R, Korrovits P, et al. Complementary seminovaginal microbiome in couples. Res Microbiol 2015;166:440-7. doi:10.1016/j.resmic.2015.03.009.

[55] Swanson GM, Moskovtsev S, Librach C, Pilsner JR, Goodrich R, Krawetz SA. What human sperm RNA-Seq tells us about the microbiome. J Assist Reprod Genet 2020;37:359-68. doi:10.1007/s10815-019-01672-x.

[56] Althouse GC, Kuster CE, Clark SG, Weisiger RM. Field investigations of bacterial contaminants and their effects on extended porcine semen. Theriogenology 2000;53:1167-76. doi:10.1016/S0093-691X(00)00261-2.

[57] Brown VG, Schollum LM, Jarvis BDW. Microbiology of bovine semen and artificial breeding practices under New Zealand conditions 2012. 
doi:10.1080/00288233.1974.10421030.

[58] Kwasniewski W, Wolun-Cholewa M, Kotarski J, Warchol W, Kuzma D, Kwasniewska A, et al. Microbiota dysbiosis is associated with HPV-induced cervical carcinogenesis. Oncol Lett 2018;16:7035-47. doi:10.3892/ol.2018.9509.

[59] Wang Y, Ametaj BN, Ambrose DJ, Gänzle MG. Characterisation of the bacterial microbiota of the vagina of dairy cows and isolation of pediocin-producing Pediococcus acidilactici. BMC Microbiol 2013;13:19. doi:10.1186/1471-2180-1319.

[60] Newell-Fugate AE, Lenz K, Skenandore C, Nowak RA, White BA, BraundmeierFleming A. Effects of coconut oil on glycemia, inflammation, and urogenital microbial parameters in female Ossabaw mini-pigs. PLoS One 2017;12. doi:10.1371/journal.pone.0179542. 


\section{CRediT authorship contribution statement}

Francisco Marco-Jiménez: Conceptualisation, Methodology, Investigation, Writing original draft, Formal analysis, Resources, Funding acquisition, Supervision. Sara Borrás: Methodology, Investigation. Ximo Garcia-Dominguez; Methodology, Investigation. Giuseppe D’Auria: Conceptualisation, Methodology, Investigation. Jose Salvador Vicente: Resources, Funding acquisition, Supervision. Clara Marin: Conceptualisation, Methodology, Investigation, Writing - original draft, Formal analysis, Resources, Funding acquisition, Supervision.

\section{Acknowledgements}

Funding from the Ministry of Economy, Industry and Competitiveness (Research project: AGL2017-85162-C2-1-R) is acknowledged. X.G.D. was supported by a research grant from the Ministry of Economy, Industry and Competitiveness (BES-2015-072429). English text version was revised by N. Macowan English Language Service. 
Figure 1. Rarefaction curve. Species collection curves determined from sequence analysis. Each inbred line represents one pooled sample obtained from 10 males in one week. A, V and LP are a synthetic breed selected from a family index based on litter size at weaning. $\mathrm{R}$ line is a synthetic breed selected on daily body weight gain.

Figure 2. Alpha Diversity Box-and-whisker plots of diversity within inbred lines. A, V and LP are a synthetic breed selected from a family index based on litter size at weaning. $\mathrm{R}$ line is a synthetic breed selected on daily body weight gain. The inbred lines of the box show the $25^{\text {th }}, 50^{\text {th }}$, and $75^{\text {th }}$ percentiles, the whiskers extend to the highest or lowest value within 1.5 times the interquartile range. A. estimated number of OTUs calculated by the Chao1 index. B. estimated alpha diversity calculated by the Shannon index. Significant differences found $(\mathrm{p}<0.05)$.

Figure 3. A. Venn diagram showing unique and shared taxa between samples among the inbred lines. A, V and LP are a synthetic breed selected from a family index based on litter size at weaning. $\mathrm{R}$ line is a synthetic breed selected on daily body weight gain. Selection criteria was based on presence or absence regardless of abundance. Not drawn to scale. Value in brackets represent the genera found in each inbred line. B. Principle Coordinate Analysis 3D plot of beta diversity analysis of inbred lines using Bray-Curtis distance.

Figure 4. Volcano plot of differentially expressed OTUs between inbred lines selected by litter performance and selected on daily body weight gain at genus levels. ANCOM analysis was performed to analyse a statistical significance $(\mathrm{p}<0.05)$. Statistically significant OTUs are represented by blue dots. 
Table 1. Effect of host genetics on sperm quality parameters in four Spanish commercial rabbit inbred lines.

\begin{tabular}{|c|c|c|c|c|}
\hline \multirow[t]{2}{*}{ SPERM QUALITY TRAITS } & \multicolumn{4}{|c|}{ INBRED LINES } \\
\hline & A & V & LP & $\mathbf{R}$ \\
\hline SELECTION CRITERIA & \multicolumn{3}{|c|}{ Litter performance } & Daily body weight gain \\
\hline \multicolumn{5}{|l|}{ General characteristics } \\
\hline Sperm concentration & $153.7 \pm 18.51^{b}$ & $308.5 \pm 18.51^{\mathrm{a}}$ & $252.0 \pm 18.51^{\mathrm{a}}$ & $125.0 \pm 18.51^{b}$ \\
\hline \multicolumn{5}{|l|}{ Sperm motility } \\
\hline Percent motility (\%) & $81.1 \pm 2.06$ & $89.7 \pm 2.06$ & $88.5 \pm 2.06$ & $83.5 \pm 2.06$ \\
\hline $\mathrm{VCL}(\mu \mathrm{M} / \mathrm{S})$ & $94.6 \pm 3.60$ & $90.4 \pm 3.60$ & $94.1 \pm 3.60$ & $99.4 \pm 3.60$ \\
\hline VSL $(\mu \mathrm{M} / \mathrm{S})$ & $40.8 \pm 2.00^{b}$ & $41.2 \pm 2.00^{\mathrm{b}}$ & $49.4 \pm 2.00^{\mathrm{a}}$ & $35.8 \pm 2.00^{\mathrm{b}}$ \\
\hline $\operatorname{VAP}(\mu \mathrm{M} / \mathrm{S})$ & $60.6 \pm 2.49^{a}$ & $59.7 \pm 2.49^{b}$ & $69.7 \pm 2.49^{a}$ & $59.3 \pm 2.49^{b}$ \\
\hline LIN (\%) & $43.8 \pm 2.3^{\mathrm{ab}}$ & $45.8 \pm 2.3^{\mathrm{ab}}$ & $52.5 \pm 2.3^{\mathrm{a}}$ & $39.0 \pm 2.3^{\mathrm{b}}$ \\
\hline STR (\%) & $67.8 \pm 1.90^{\mathrm{a}}$ & $68.9 \pm 1.90^{\mathrm{a}}$ & $70.9 \pm 1.90^{\mathrm{a}}$ & $60.3 \pm 1.90^{\mathrm{b}}$ \\
\hline WOB (\%) & $64.4 \pm 1.76^{b}$ & $66.1 \pm 1.76^{b}$ & $74.1 \pm 1.76^{\mathrm{a}}$ & $63.9 \pm 1.76^{b}$ \\
\hline $\mathrm{ALH}(\mu \mathrm{M})$ & $2.8 \pm 0.10^{\mathrm{a}}$ & $2.5 \pm 0.10^{\mathrm{b}}$ & $2.5 \pm 0.10^{\mathrm{b}}$ & $2.7 \pm 0.10^{\mathrm{a}}$ \\
\hline $\mathrm{BCF}(\mathrm{HZ})$ & $12.2 \pm 0.22^{\mathrm{a}}$ & $11.2 \pm 0.22^{b}$ & $10.0 \pm 0.22^{c}$ & $9.9 \pm 0.22^{c}$ \\
\hline \multicolumn{5}{|l|}{ Integrity of the plasma membrane } \\
\hline Viability (\%) & $92.4 \pm 2.41$ & $93.1 \pm 2.41$ & $85.4 \pm 2.41$ & $87.9 \pm 2.41$ \\
\hline \multicolumn{5}{|l|}{ Morphology } \\
\hline Abnormal sperm (\%) & $12.0 \pm 1.76^{b}$ & $17.8 \pm 1.76^{\mathrm{a}}$ & $17.9 \pm 1.76^{\mathrm{a}}$ & $11.1 \pm 1.76^{\mathrm{b}}$ \\
\hline Intact apical ridge (\%) & $91.4 \pm 0.98^{b}$ & $96.6 \pm 0.98^{a}$ & $97.6 \pm 0.98^{a}$ & $95.9 \pm 0.98^{a}$ \\
\hline Total pooled samples* & 10 & 10 & 10 & 10 \\
\hline
\end{tabular}

$A, V$ and LP are a synthetic breed selected from a family index based on litter size at weaning. $R$ line is a synthetic breed selected on daily body weight gain. VCL: curvilinear velocity, VSL: straight-line velocity, VAP: average path velocity, LIN: linearity index, STR: straightness, WOB: wobble, ALH: amplitude of lateral head displacement, BCF: beat cross frequency. * Each pool was constituted from 10 males. Data are expressed as least square means \pm standard error of means. ${ }^{a, b, c}$ Values within a row with different superscripts $\operatorname{differ}(p<0.05)$ 
Table 2. Influence of genetics on fertility in four Spanish commercial rabbit inbred lines.

\begin{tabular}{cccccccc}
\hline \multirow{2}{*}{ Inbreed lines } & $\begin{array}{c}\text { Females* } \\
\text { (n) }\end{array}$ & $\begin{array}{c}\text { Matings } \\
\text { (n) }\end{array}$ & Total & $\begin{array}{c}\text { Matings } \\
(\mathbf{n})\end{array}$ & Non lactating females & $\begin{array}{c}\text { Matings } \\
(\mathbf{n})\end{array}$ & Lactating females \\
\hline A & 62 & 136 & $82.4^{\mathrm{a}}$ & 28 & $92.6^{\mathrm{a}}$ & 108 & $79.6^{\mathrm{a}}$ \\
V & 58 & 134 & $79.1^{\mathrm{a}}$ & 33 & $93.9^{\mathrm{a}}$ & 101 & $74.3^{\mathrm{a}}$ \\
LP & 52 & 117 & $89.7^{\mathrm{a}}$ & 32 & $96.9^{\mathrm{a}}$ & 85 & $87.1^{\mathrm{a}}$ \\
R & 68 & 107 & $60.7^{\mathrm{b}}$ & 54 & $71.4^{\mathrm{b}}$ & 53 & $50.9^{\mathrm{b}}$ \\
\hline
\end{tabular}

*Multiparous females at different parity order (3-6). The same female was mating twice as a maximum along this study. All males contributed fertility data with at least ten matings. ${ }^{a, b}$ Values within a row with different superscripts differ $(p<0.05)$. n: number of data. 


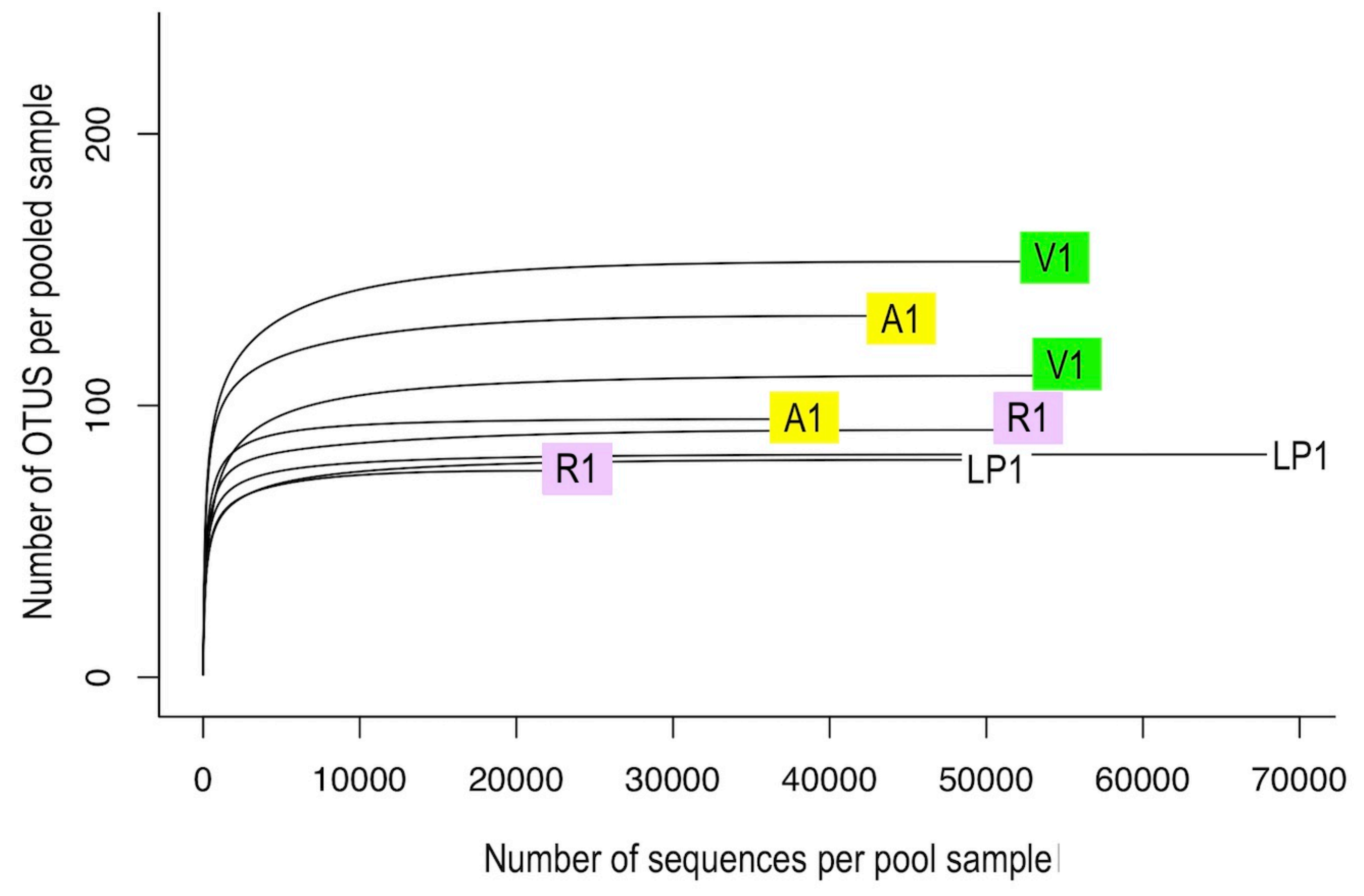


A

B

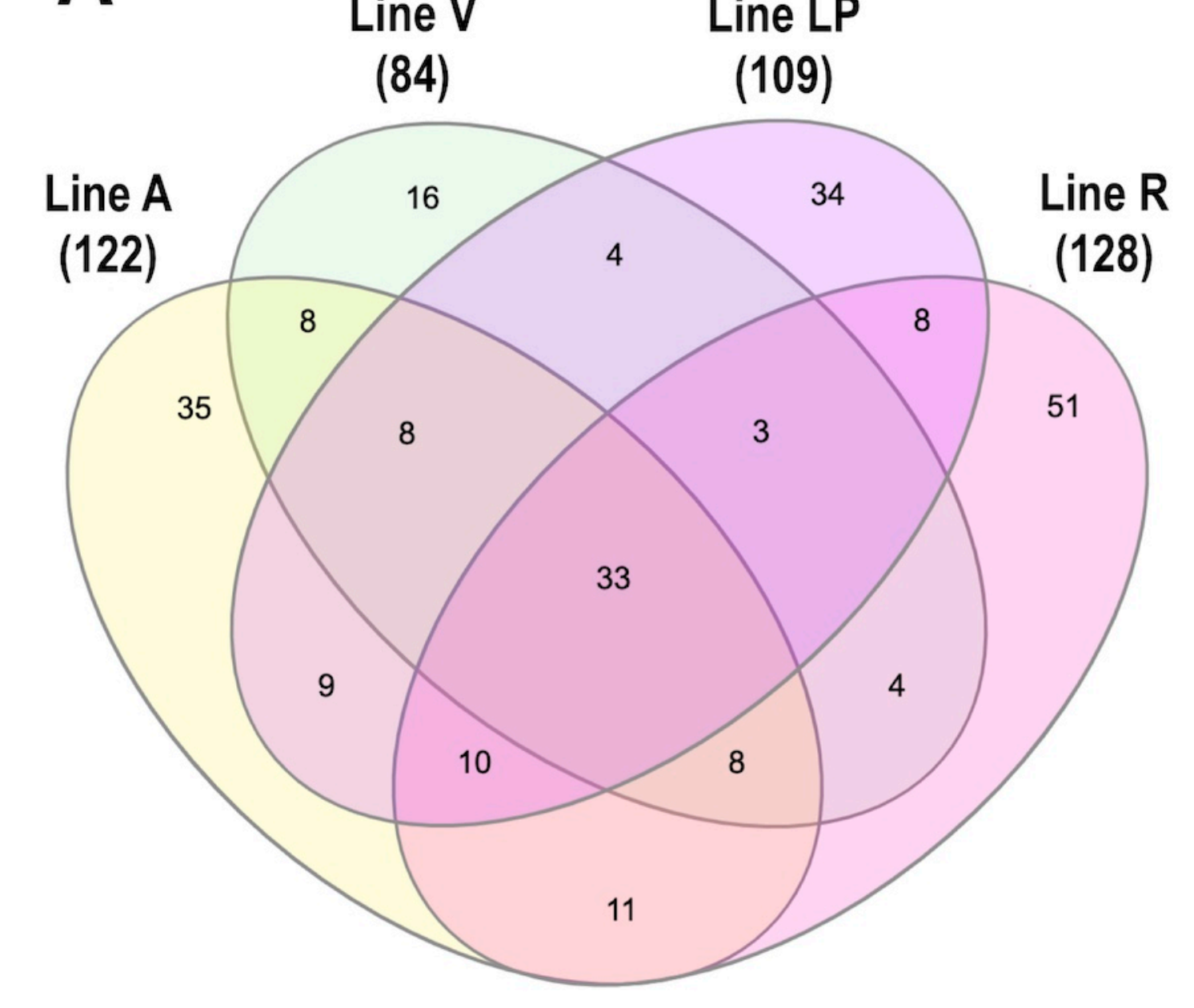

\author{
Inbred line
}

- A

- LP

- $\mathrm{R}$

- V

○

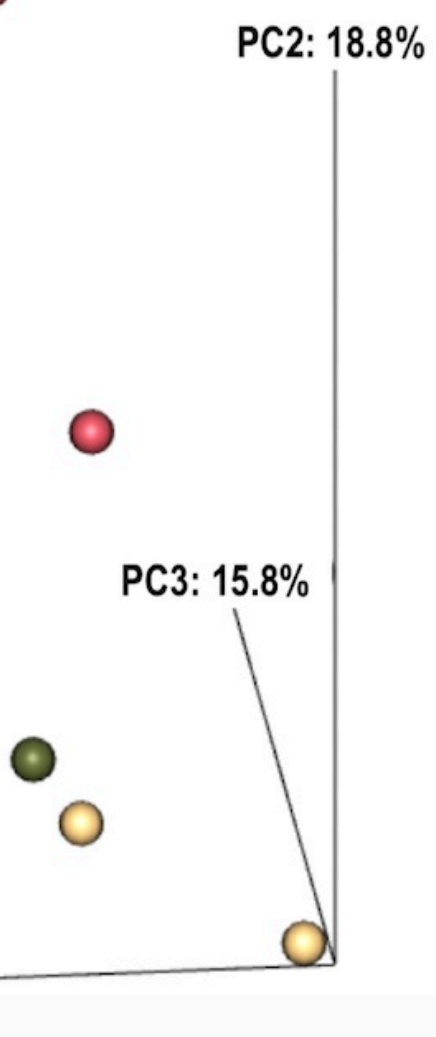

PC1: $24.9 \%$ 


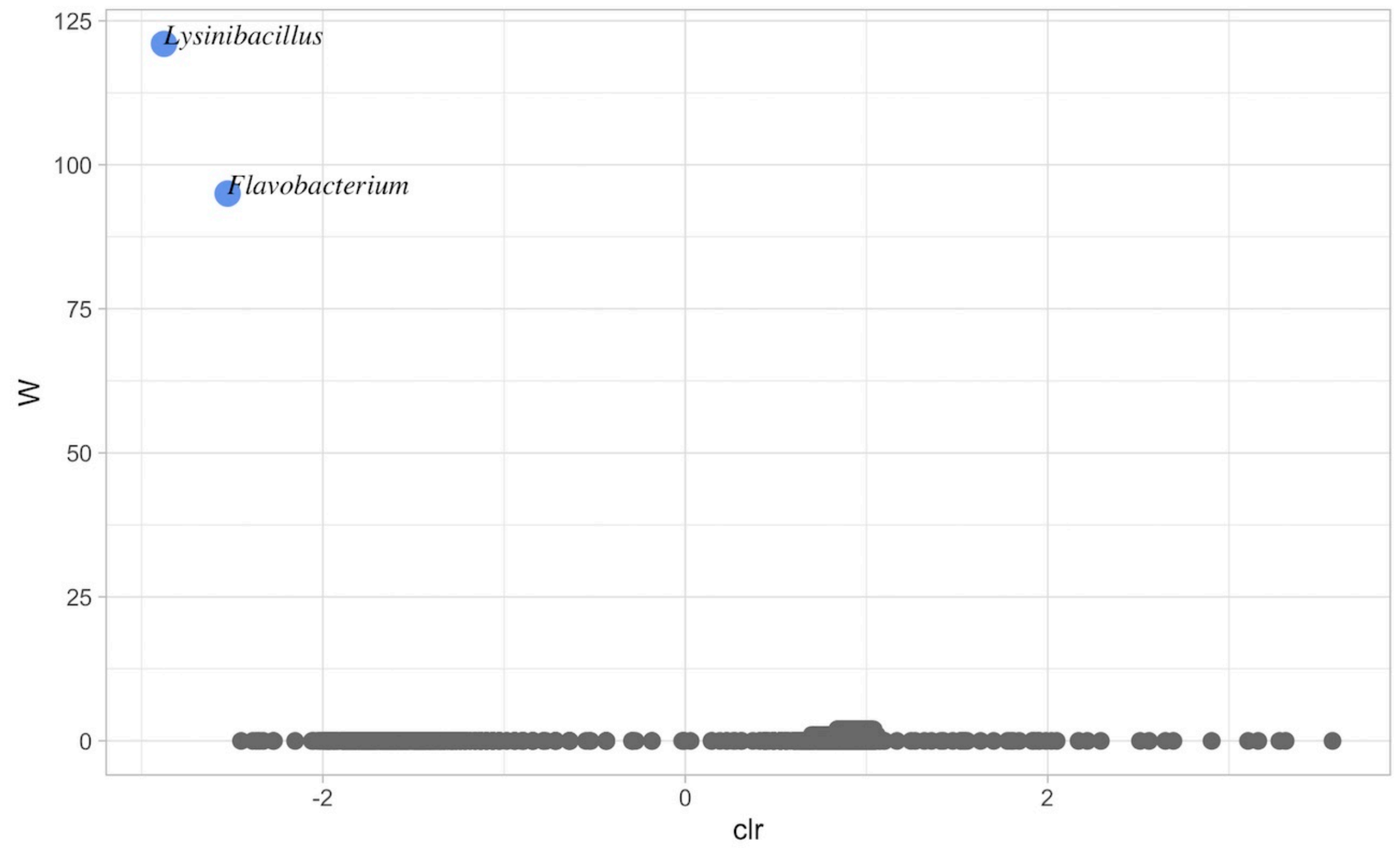

